opportunity is taken of confirming the diagnosis made. The operation is a very simple one and if carried out with the usual precautions is attended by no risks whatever.

Differential diagnosis. - Meningitis may be a complication of many diseases-namely, pneumonia, influenza, enteric fever, glanders, plague, tuberculosis, and extension from middle-ear disease, \&c. In those other diseases, however, a previous history of sickness will be furnished, and the clinical symptoms of the particular disease should be evident before extension to the meninges has occurred. In making an examination of a suspicious case of cerebro-spinal fever the lungs should always be examined and pneumonia eliminated. In young children I agree that this is sometimes difficult, but the embarrassed breathing and disturbed pulse-respiration ratio should be of great assistance in arriving at a diagnosis. In cerebro-spinal fever the pulse-respiration ratio is unaffected, and the respiration is seldom laboured as in pneumonia. A diagnosis from influenza is probably the most difficult, but even here the history should be of value, and great pain in the joints is uncommon in cerebro-spinal fever. Tuberculous meningitis has generally a more gradual onset, a less violent headache, and a more regular course than cerebro-spinal fever. Otitis media with extension to the meninges should present little difficulty as a previous history of a discharge from the ear will be given. When called upon to see a case of cerebro-spinal fever it is my universal practice to refrain from examining the patient until I have written down the history after careful cross-examination of the parents, and what strikes one most in connexion with almost all the cases of cerebro-spinal fever with which we have had to deal in $\mathrm{Gl}$ isgow is the sudden onset, intense frontal or occipital hi ad iche and vomiting more or less continuous, followed by great irritability and general hyperæsthesia. know of no other disease presenting such a picture as one usually meets with, where the patient, previously well and fit, is so suddenly struck down without previous warning, becoming soon after very ill and usually delirious.

Conclusion.-In the past many deaths in Glasgow, as elsewhere, have been certified as simple meningitis, idiopathic meningitis, acute meningitis, occasionally septic or suppurative meningitis, or posterior basal meningitis. I have had difficulty in understanding what is meant by simple or idiopathic meningitis. I have always wondered, as doubtless others have wondered, what caused the meningitis, and in the absence of any other definite information as to what is the true causative micro-organism I feel justified in concluding they should fall within the category of cerebro-spinal fever. I am not one of those who attach any importance to the term "simple" or "idiopathic," and prefer to put the query, What caused it? - as undoubtedly there was a cause Acute, septic, suppurative, and posterior basal meningitis for the same reason must now be relabelled "cerebrospinal fever." Further, I believe that some cases certified in the past as tuberculous meningitis were really cases of "cerebro-spinal fever." In order to satisfy myself on this point I have inquired into the history of some of those cases and have been told that the child had only been ill for periods varying between two, four, and six days. Other deaths also have been certified as due to "teething and convulsions." I put the question to you, gentlemen, Does it conform to any of the laws of nature that a child should die because it is getting teeth? I have difficulty in understanding this also, and in the absence of further information $I \mathrm{am}$ inclined to the view that at least some of those cases are also cases of cereb-o-spinal fever. Further, it is conceivable that some deaths registered as due to "acute gastritis" and probably also "summer diarrhœa" may really be actual cases of cerebro-spinal fever.

Glasgow.

\section{THE TREATMENT OF CANCER.}

BY LOVELL DRAGE, M.A., M.D. OxON., MEDICAL OFFICER OF HEALTH, HATFIELD RURAL DISTRICT, ETC.

IN the year 1902 I published a paper in The LanCeT ${ }^{1}$ calling the attention of the medical profession to the amelioration in the condition of patients suffering from cancer by the artificial production of what is technically known as leucocytosis, which denotes an increase in those cells of the blood which are most highly endowed with the properties of living cells. The first agent used for the purpose was the cinnamate of sodium, and I was led to use the drug because of clinical observations previously made upon patients suffering from cancer and who were treated with the oil of cinnamon. With the aid of my friend, Mr. G. T. Morgan, D.Sc. Lond of the Royal College of Science, Sonth Kensington, I have since then made an attempt to test various other organic salts closely related to the cinnamate of sodium.

Several papers referring to the results of the treatment have been published in the two principal medical journals, and it will be well to analyse the reasons why, after so many years of uphill work, no convincing results have been obtained. Surgery, so far, has held the field in a manner which is surprising to one like myself who, after 23 years of professional life, has known no permanently successful result secured by surgical methods in the treatment of this disease among patients, friends, or acquaintances. The failure of surgery is to $\mathrm{my}$ mind absolute, although all cases, except the worst possible ones, are included in its net. It is expected of anyone who challenges the surgeon, as I do, to compare results from cases of every degree of advance. ment in the disease, up to the worst, with those obtained from cases of the most favourable kind. The only four early cases which I have been able to secure have all succeeded. It is true that in one case the growth was removed by the knife, but the operation of simple removal was one which surgeons call criminal because of its want of completeness. Criminal or not, the patient remains well and at work after more than six years, when according to the rules of surgery she should have died long ago, or at all events been incapacitated from earning her living. One alone of the four is dead, and death was caused by heart disease after the complete disappearance of the growth. Another case, that of a nurse who refused operation, remains well and at work after four years, after fearing that the pain from the growth from which she was suffering would incapacitate her for her work. Another case, recurrent after operation, remains well after an equal interval of time. A fifth is still under treatment, the growth and the infected glands having much diminished in size.

Microscopical examination was not possible in all of these cases although it was made in the only two in which it was possible. This statement leads to the indication of another difficulty in establishing a medical treatment-namely, the want of microscopical examination. A mere clinical diagnosis, although such can be made with very considerable accuracy in the majority of cases in which sight and touch are available, is not held to be worth anything by the advocates of surgical procedure.

Now it must not be inferred that a claim to any finality in treatment is advanced, but a claim is made that the treatment advocated possesses a sound basis, and that the drugs which Dr. Morgan has made for the first time, such as the coumarate of sodium and tylmarin. are capable of exercising a very beneficial effect, even in cases of the worst possible type. As has previously been indicated, the stock-in-trade of the physician, so far as cancer is concerned, is composed chiefly of cases advanced in the disease, cases which have been treated with the knife, with the various light treatments, or with electricity, the class of case which I had never succeeded in alleviating until the time came when I founded for myself a new basis of treatment. The pleasure derived from giving alleviation of any substantial kind to such cases has been very considerable, and the disappointment of inability to proceed faster very great. A consideration of the facts obtained from the treatment of a considerable number of patients in the later stages of the disease leads me, however, to the belief that the advance made is great, although at the present time it is impossible to assert that all cases of cancer can be cured by medicinal treatment.

The term "cancer" connotes a disease which is caused by a cellular degeneration - the cells thus degenerated possessing the power of self-multiplication. As cellular multiplication increases, various troubles to the human frame result. The simplest form of trouble is injury by pressure of the growth upon adjacent organs, by interference with the lumen of natural passages, or by destruction of the organ invaded. The next simplest trouble is the local death of the tissues invaded, with the resultant absorption of the products of decomposition into the economy. A much more complex phenomenon is the spread of the disease from the seat of origin and the infection of other organs or structures. Still more complex is the condition known as "the cancerous 
cachexia"-i.e., the general condition of ill-health, which includes the wasting of the body and its death. A study of the results obtained from medicinal treatment of such various conditions brings important facts to light and helps to clear the ground for the discovery of an instrument of -destruction for the disease when first diagnosed.

Except in the cases mentioned at the commencement of this paper no results can be claimed which can be called. certain results upon an external growth of any long standing, but in several cases the diminution in size of lymphatic glands secondarily infected has been marked, and no fresh invasion of lymphatic glands has been noted after the commencement of treatment. This observation is important, because the lymphatic system is so frequently the path by which infection travels. In two cases of abdominal cancer, both diagnosed by surgeons of repute after an exploratory operation, a complete restoration to health has been obtained. The first of these cases was published in the British Medical Journal of Oct. 28th, 1905. The patient was under the care of a medical man who obtained from me the details of treatment ; he was able to report to me in October, 1905 :-" "The tumour is no larger, I think it is smaller; there is no pain, although this was present before the commencement of the treatment ; the general health is very good, better than for some time previously." It is only right to say that the operating surgeon when a report was sent to him wrote:-"About the diagnosis, it was wrong. I have little doubt in the light of subsequent events that what we took to be carcinomatous nodules must, I suppose, have been inflammatory. Yet I erred with my eyes open, because I have already read a paper which was afterwards published on this very condition." The query is, perhaps, pertinent: What is the disease which can so deceive a surgeon of experience and two other medical gentlemen present at the operation? And how many of the successes claimed by surgeons are cases of this unknown disease?

The second case came under my care during the last winter. The patient was operated upon by Mr. A. A. Bowlby in St. Bartholomew's Hospital in April, 1906, who found a cancer of the liver. After operation the patient was told that this was incurable and that nothing further could be done for her. When I first saw this patient she was losing flesh, was in pain, and was suffering from slight jaundice. She has just now returned from a convalescent home and has been examined at St. Bartholomew's. Her condition is most favourable, she herself believing that she is absolutely cured. No judgment as to permanence of cure can be given for many years, but at all events the fact remains that the woman's life has been prolonged and she has obtained alleviation from her sufferings.

Two cases of obstruction of the gullet have been certainly relieved. The first was treated by Mr. C. B. Lockwood at St. Bartholomew's Hospital, to whom I am eternally indebted for the interest which he has taken in my work. His house surgeon wrote to me on Dec. 12th, 1906: "One of Mr. Lockwood's patients who is suffering from cancer of the gullet has greatly improved on your treatment. After ten injections he has put on a stone in weight and from being practically unable to swallow fluids can now take about a pint in five minutes." This patient died unfortunateiy from bronchopneumonia, as was ascertained by the necropsy, and not from the disease.

The second case was treated by myself. The patient refused operation when pressed to submit to one by an eminent surgeon in October, 1906. He came under my treatment early in November and was then losing 4 pounds in weight weekly. His powers of swallowing increased and he first ceased to lose, and then gained, weight. Six weeks before death he gradually began to lose ground and the obstruction gradually increased until death occurred, eight months after our first interview.

The escape from surgical methods in these two cases, although life was not saved, implies a considerable advance. Palliative methods which are available for the surgeon do not provide anything but a life of misery to the patient, and further work on chemical lines is encouraged by such results. Such work is proceeding.

As coöperation was found to be difficult in this country a report was obtained by Dr. Morgan from a laboratory in Buffalo, New York, which recommended a reinforcement of the coumaric acid salts at present used, and resulting from this various metallic salts are being tried. It appears probable that if the right combination can be secured success will follow, but no definite decision can be given on this point at the present moment.

Very definite results have been obtained in connexion with the prevention of the local death of the tissues invaded and the absorption of the products of decomposition into the human economy. In old days my experience was that a large proportion of patients died septic, while no case which I have treated by the new method has so died. The reason for this is probably that all the drugs used are very active in destroying fission fungi, those agents at once of destruction and disease. When tested by the Rideal-Walker method against the bacillus typhosus, the activity of carbolic acid being 1 , that of tylmarin was found to be 4.5 and that of the ortho-coumaric acid $6 \cdot 5$, whilst that of formalin, which is a very active substance, is only $0 \cdot 30$.

In connexion with the prevention of the cancerous cachexia it is no part of my present intention to enter upon the various complex elements which cause it. It is, however, clear in my mind that the treatment advocated produces a great stimulating effect and consequently a prolongation of life and increase of comfort to the sufferer. For many years past physicians in this country have been too much led instead of themselves leading. Many have been content with a profound scepticism as to the results obtained by the use of the curative part of their art, many with the copying of foreign methods and modes of thought, and too many with just the use of any new drug introduced by manufacturers. It appears to me that it should be the rôle of the physician to initiate rather than to follow, and that the present pessimism as to the possibility of treating cancer by therapentic methods is an attitude to be ashamed of. At no time have so many active remedies been in the hands of physicians and at no time have there been so many suggestive facts obtained from scientific laboratory researches for their use. At the present moment surgery is supreme simply because medicine has so long suffered from timehonoured prejudices and a reluctance to emerge from beaten tracks.

Hatfield.

\section{THE SOLUBILITY OF AIR IN FATS AND ITS RELATION TO CAISSON DISEASE. ${ }^{1}$}

BY HORACE M. VERNON, M.D. OXON., FELLOW OF MAGDALEN COLLEGE, OXFORD.

(From the Physiological Laboratory, Oxford.)

As is now well known, the very varied symptoms produced by rapid decompression from high atmospheric pressures, and popularly known as "caisson disease" or "diver's palsy," are due to liberation of bubbles of gas-chiefly nitrogen-in the blood and tissues. In the course of a recently published investigation I found that air is much more soluble in certain oils than in water. Dr. J. S. Haldane pointed out to me the interest of this fact in connexion with the causation of caisson disease and at his suggestion I have repeated and extended my observations.

The fats experimented with were olive oil, cod-liver oil, and lard. In the case of the first two the solubility was measured at $15^{\circ}$ and at $37^{\circ} \mathrm{C}$., whilst for lard it was determined at $45^{\circ} \mathrm{C}$. In the observations made at room temperature the oil was shaken violently with air in a bottle for several minutes and was allowed to stand for from one to one and a half hours till all the air bubbles had risen to the surface. It was then weighed, and about 40 to 50 grammes of it were sucked up into the vacuous flask of a Geissler's mercury pump. This flask contained from 70 to 100 cubic centimetres of 0.5 per cent. sulphuric acid which had previously been well boiled for an hour so as to get rid of all traces of air. The mixture of oil and water was now boiled for half an hour, the oil breaking up into a very fine emulsion and giving up practically all of its gas in the first few minutes. This gas was pumped off and analysed with Haldane's ${ }^{2}$ gas analysis apparatus. The oil was boiled with dilute acid instead of water, so as to obtain the whole of the carbon dioxide present, both combined and in solution. In determining the solubility at $37^{\circ}$, the oil, previously saturated at room temperature, was

1 A paper read before the Royal Society on May 30th, 1907.

2 Haldane : Journal of Physiology, vol. xxii., p. 465, 1893 